\title{
The combined effect of music and frequency therapy from the BioCor device on stress level in humans
}

\begin{abstract}
Goals and objectives of the study: The goal of this paper was to study combined effect of music and frequency therapy from the BioCor device on stress levels in humans.

Study design: Using GDV/ Bio-Well technology the effect of music and frequency therapy for 10 minutes to human anxiety level for a group of 30 participants was studied with the Mood Mapping Profile Questionnaire and Bio-Well technology, compared with 30 participants resting for 10 minutes.
\end{abstract}

Results: The statistically significant positive effect after 10minutes of therapy was demonstrated for all the participants, but stronger effect was recorded for women participants. No changes were recorded for a control group.

Conclusions: This study confirms the efficiency of the combined action of music and frequency therapy.

Keywords: music therapy, psychophysiology, mood, gender, emotions, electrophotonic imaging, bio-well, BioCor
Volume 13 Issue 2 - 2020

\section{Konstantin Korotkov}

Federal State Budget Institution "Saint-Petersburg ScientificResearch Institute for Physical Culture”, Russia

Correspondence: Konstantin Korotkov, Federal State Budget Institution "Saint-Petersburg Scientific-Research Institute for Physical Culture", St. Petersburg, Russia, Russia,

Email korotkov2000@gmail.com

Received: March 13, 2020 | Published: March 31, 2020
Abbreviations: EPI, electro photonic imaging; GDV, gas discharge visualization; $\mathrm{CCD}$, charge-coupled device; StD, standard deviation; EMR, electro magnetic radiation

\section{Introduction}

As shown in the review, ${ }^{1}$ the number of studies on emotional response to music increases in the last decades. Many of those researches suggest that individual differences in empathy, alexithymia, personality traits, and musical expertise might play a role in musicperceived emotions. ${ }^{2,3}$ Several kinds of researches demonstrated gender differences in emotional and psychophysiological responses to music. ${ }^{4,5}$ Many emotions are closely related to stress, and music listening has a beneficial impact on health via stress-reducing effects. ${ }^{6,7}$ The aim of this paper was to study the combined effect of music and frequency therapy on stress levels in humans.

\section{Study design}

A total of 60 female and male volunteer subjects between 18 and 53y.o. were recruited for the study, 45 females and 15 males. Participants signed an informed consent form explaining the aims and protocol of the experiments. Subjects were screened for wellness; exclusion criteria included conditions that could compromise physical and mental health, such as:
a. Severe chronic diseases,
b. Acute somatic, neurological diseases,
c. Receiving medicines and dietary supplements during the experiment,

d. Clinically significant changes in functional indicators that indicate undiagnosed disease and require additional screening,

e. Clinically detectable mental pathology.

People's level of stress was evaluated with the Bio-Well device initially and then all participants were randomly divided into two groups: control and experimental. Participants from the control group rested for 10minutes in a quiet room and then measurements were repeated. Participants from the experimental group experienced the combined effect of the music and frequency therapy for 10minutes from the BioCor device, and then measurements with the Bio-Well device were repeated.

\section{Methods}

The technique of Electrophotonic Imaging (EPI) allows the recording, from a living subject, of electron and photon emission stimulated by an electromagnetic field. The train of short electric impulses $(10$ microsec) on the camera plate stimulates biological subjects and generates a response in the form of excited gas plasma (that is why in physical terms this approach is known as Gas Discharge Visualization - GDV). ${ }^{8-10}$ Plasma emits light which is directly measured by a charge-coupled device (CCD), the state of the art in measuring low-level light that is used in astrophysics and other scientific endeavors. The CCD registers the pattern of photons detected over time. The digital data are transmitted directly into a computer for data processing, and each image from the light emitted is stored as a graphics file. The two-dimensional images of the light are then used to calculate the area, emission intensity, fracticality, and other parameters. What was previously considered as confounding parameters (such as pressure, finger size, sweating, or changes in 
physical conductivity) in the older forms of electrophotography have been demonstrated by different researchers to be resolved by the new EPI method. Researchers report replicability of findings across different experimenters, different cameras, and different countries. ${ }^{11}$ The EPI technique has been found to be effective in evaluating the state of individual human health, ${ }^{12-14}$ and in monitoring individual reactions to different kinds of training. ${ }^{15-17}$

The Mood Mapping Profile Questionnaire ${ }^{18}$ was designed around eight descriptors, or adjectives, to evaluate mood states of subjects (grounded, inspired, focused, aware, energized, balanced, relaxed, peaceful). Subjects were asked to rate how well each of the adjectives described their current emotional state on a 5-point scale of intensity from "not at all" (1) to "extremely" (5). Subjects completed identical scales before and after treatment.

The device for treatment, having brand name BioCor (producer www.bio-well.com) is based on a music file individually modified in the Bio-Well programs based on the results of the subject's measurement. ${ }^{9,18}$ In the system we are using an original meditation 10 minutes music composition (composed by Kimba Arem) played using seven crystal Tibetan bowls that have a strong relaxation effect. ${ }^{19}$ From the two-dimensional images generated by the EPI software we calculate the Standard Deviation (StD) of the external contour of the image and compare $\mathrm{StD}$ of a current person with the $\mathrm{StD}$ of an apparently healthy person based on the statistics of 200,000 people kept in our database. The mismatch signal is used to modify the music file using a special algorithm. Music is served by headphones in wav format. Simultaneously with the music electromagnetic radiation of extremely high-frequency (EHF EMR) from GaAs diode in the range $40-60 \mathrm{GHz}$ of very low intensity is applied to the forehead of a subject.

Electromagnetic waves of millimetric type have a low capacity of penetration into biological tissue $(0.2-0.8 \mathrm{~mm})$, and are almost completely absorbed by the superficial layers of the skin (molecules of water, hydrated collagen molecules, cells of connective tissue), without any thermal action. Therefore, the EHF waves do not act directly on the patient's internal organs. EHF signals are similar to the signals which are generated from cell membranes, these signals accelerate different biochemical reactions, alter enzyme activity, reinforcing or weakening intercellular connections. In comprehensive clinical studies first in Russia, and then worldwide was demonstrated that EHF EMR has healing effects. ${ }^{20-23}$

\section{Results}

Before and after treatment results from the Mood Mapping Profile Questionnaire were analyzed with dependent t-test. All subjects from the experimental group perceived themselves in a better mood state after the treatment; the increase from baseline was statistically significant at $\mathrm{p}<0.05$ (Table 1) for all measured parameters except "Focused" parameter. Two male subjects perceived themselves, however, with less energy, as less aware, and as less grounded.

Table I Comparison of different mood states for the participants of the experimental group before-after treatment for 30 participants from the experimental group

\begin{tabular}{|c|c|c|c|c|c|}
\hline Grounded & & & Inspired & & \\
\hline Before & After & $P$ value & Before & After & $P$ value \\
\hline $2.0+/-0.02$ & $1.3+/-0.03$ & 0.04 & $1.6+/-0.04$ & $2.5+/-0.03$ & 0.04 \\
\hline Focused & & & Aware & & \\
\hline Before & After & $P$ value & Before & After & $P$ value \\
\hline $2.1+/-0.08$ & $1.7+/-0.07$ & 0.6 & $2.5+/-0.04$ & $1.3+/-0.06$ & 0.006 \\
\hline Energized & & & Balanced & & \\
\hline Before & After & $P$ value & Before & After & $P$ value \\
\hline $2.7+/-0.8$ & $1.6+/-0.02$ & 0.01 & $1.7+/-0.07$ & $3.2+/-0.04$ & 0.02 \\
\hline Relaxed & & & Peaceful & & \\
\hline Before & After & $P$ value & Before & After & $P$ value \\
\hline $1.6+/-0.10$ & $3.5+/-0.07$ & 0.006 & $3.5+/-0.04$ & $4.1+/-0.03$ & 0.03 \\
\hline
\end{tabular}

In Bio-Well test statistically significant difference was found for the participants of the experimental group for Stress coefficient $(\mathrm{p}<0.001$, Figure 1), while another parameters tendency was positive, but not statistically significant. At the same time, when we eliminated data for 5 males from the calculations, results became statistically significant for Stress $(\mathrm{p}<0.001$, Figure 2), Energy $(\mathrm{p}=0.034)$, Balance $(\mathrm{p}=0.043)$ and Form Coefficient $(\mathrm{p}=0.052)$. No significant changes were found for the participants of the control group. 


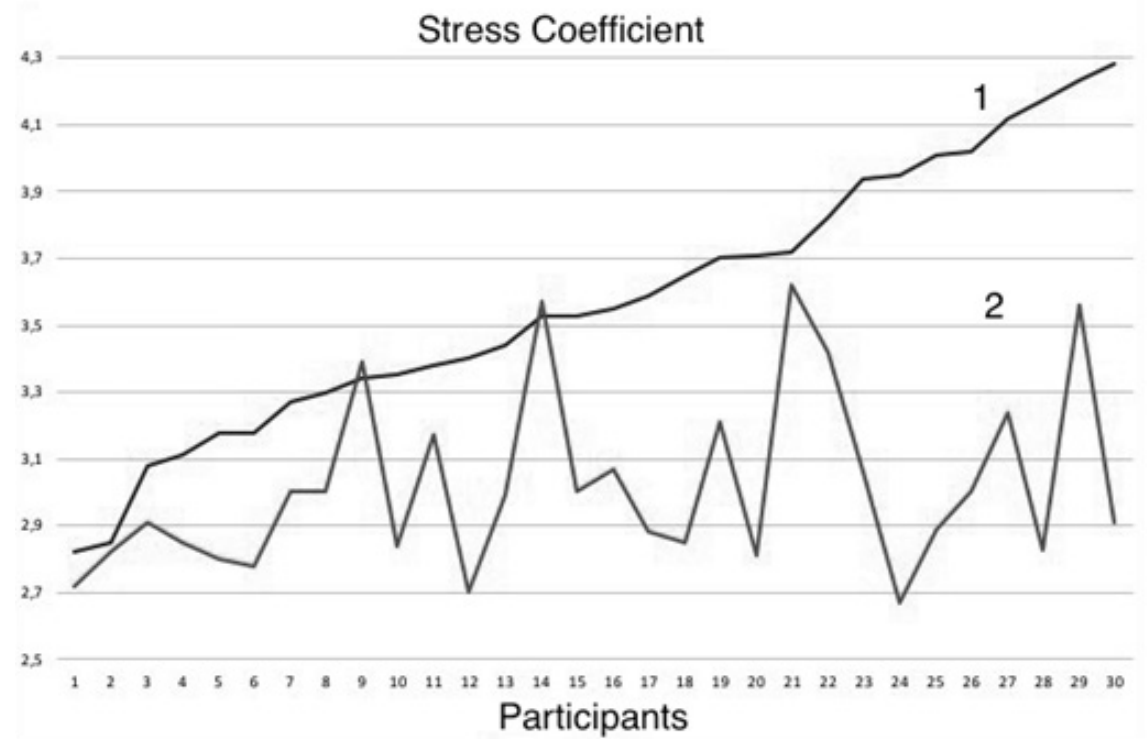

Figure I Comparison of Stress Coefficient for 30 participants of the experimental group before and after combined action of music and frequency therapy. Results of the first test were randomized by the degree of increase and compared with the results for the same participants after the therapy. I - initial, $2-$ after therapy.

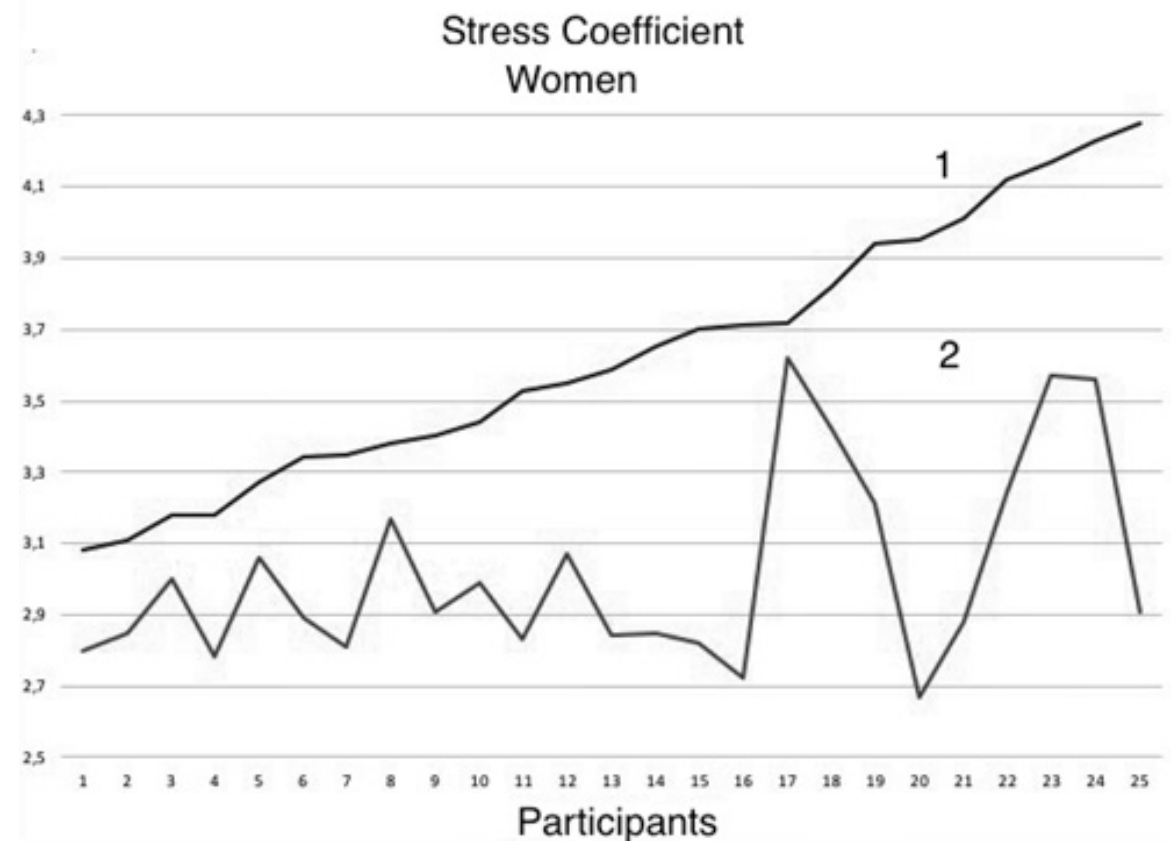

Figure 2 Comparison of Stress Coefficient for 25 women participants of the experimental group before and after combined action of music and frequency therapy. Results of the first test were randomized by the degree of increase and compared with the results for the same participants after the therapy. I - initial, 2 - after therapy.

\section{Discussion}

This paper reports the results of a pilot study in a short period after the music treatment. We plan to conduct more comprehensive research studying the effect of combined action of music and frequency therapy during a month and see the effect on several psychophysiological parameters including immune status. But even a preliminary study it confirmed the efficiency of combined action of music and frequency therapy and demonstrated a stronger effect for women participants.

\section{Limitations of the study}

This investigation should be considered as a pilot study, as the study includes different age groups, sexes, and professions included in a small cohort, it becomes even more complicated to draw any conclusions. We hope that the presented results stimulate the development of new studies, dedicated to the influence of music on human health and wellbeing. 


\section{Conclusion}

This study confirms the efficiency of the combined action of music and frequency therapy.

\section{Acknowledgments}

None.

\section{Conflicts of interest}

Author declares that there are no conflicts of interest.

\section{Funding}

None.

\section{References}

1. Eerola T, Vuoskoski JK. A Review of Music and Emotion Studies: Approaches, Emotion Models, and Stimuli. Music Perception: An Interdisciplinary Journal. 2012;30:307-340.

2. Taruffi U, Allen R, Downing J, et al. Individual Differences in MusicPerceived Emotions: The Influence of Externally Oriented Thinking. Music Perception: An Interdisciplinary Journal. 2017;34(3):253-266.

3. Juslin PN, Sloboda J. Handbook of music and emotion. USA: Oxford University Press; 2010.

4. Nater UM, Abbruzzese E, Krebs M, et al. Sex differences in emotional and psychophysiological responses to musical stimuli. International Journal of Psychophysiology. 2006;62(2):300-308.

5. McFarland RA, Kadish R. Sex differences in finger temperature response to music. International Journal of Psychophysiologie. 1991;11(3):295298.

6. Pelletier CL. The effect of music on decreasing arousal due to stress: a meta-analysis. Journal Music Therapies. 2004;41(3):192-214.

7. Khalfa S, Bella SD, Roy M, et al. Effects of relaxing music on salivary cortisol level after psychological stress. Annals of NY Academy of Science. 2003;999(1):374-376.

8. Korotkov KG, Orlov DV, Williams BO. Application of Electrophoton Capture (EPI) Analysis Based on Gas Discharge Visualization (GDV) Technique in Medicine: A Systematic Review. Journal of Alternative and Complementary Medicine. 2010;16(1):13-25.

9. Korotkov KG. The Energy of Health. USA: Amazon.com publishin; 2017.

10. Korotkov KG. Review of EPI papers on medicine and psychophysiology published in 2008-2018. International Journal of Complementary and Alternative Medicine. 2018;11(5):311-315.

11. Muehsam D, Chevalier G, Barsotti T, et al. An Overview of Biofield Devices. Global Advances in Health Medicine. 2015;4:42-51.
12. Korobka IE, Yakovleva TG, Korotkov KG, et al. Electrophotonic Imaging technology in the diagnosis of autonomic nervous system in patients with arterial hypertension. Journal of Applied Biotechnology and Bioengineering. 2018;5:112-118.

13. Buck KH, Novelli C, Costa FT, et al. Use of electro biographic photo on comparinson Among breast cancer, healthy sedentary, and healthy runners women. Centro de Pesquisas Avançadas em Qualidade de Vida. 2016;8(2):9-11.

14. Yakovleva EG, Buntseva OA, Belonosov SS, et al. Identifying Patients with Colon Neoplasias with Gas Discharge Visualization Technique. The J of Alt Comp Med. 2015;21(11):720-724.

15. Kushwah KK, Nagendra HR, Srinivasan TM. Effect of Integrated Yoga Program on Energy Outcomes as a Measure of Preventive Health Care in Healthy People. Central European Journal of Sport Sciences and Medicine. 2015;12(4):61-71.

16. Shiva KK, Srinivasan TM, Nagendra HR, et al. Electrophotonic Imaging Based Analysis of Diabetes. Int J Complement Alt Med. 2016;4(5):00134.

17. Sushrutha S, Hegde M, Nagendra R, et al. Comparative study of Influence of Yajña and Yogāsana on stress level as Measured by Electron Photonic Imaging (EPI) Technique. International Journal of Science and Research. 2014;3(8):1402-1406.

18. McNair D, Lorr M, Doppleman L. POMS Manual for the Profile of Mood States. USA, San Diego, CA: Educational and Industrial Testing Service; 1971.

19. Goldsby T, Goldsby M, McWalters M, et al. Effects of Singing Bowl Sound Meditation on Mood, Tension, and Well-being: An Observational Study. Evidenced Based Complementary and Alternative Medicine. 2017;22(3):401-406.

20. Betskii OV, Devyatkov ND, Kislov VV. Low intensity millimeter waves in medicine and biology. Review in Biomedical Engineering. 2000;28(12):247-68.

21. Bhargav H, Srinivasan TM, Varambally S, et al. Effect of mobile phone induced electromagnetic field on brain haemo-dynamics and human stem cell functioning. possible mechanism link to cancer risk and early diagnostic values of electrophotonic imaging. Journal of Stem cells. 2015;10:287-294.

22. Gapeyev AB, Mikhailik EN, Chemeris NK. Anti-inflammatory effects of low-intensity extremely high-frequency electromagnetic radiation: frequency and power dependence. Bioelectromagnetics. 2008;29(3):197206.

23. Usichenko TI, Edinger TL, Gizhko V, et al. Low-Intensity Electromagnetic Millimeter Waves for Pain Therapy. Evidenced Based Complementary and Alternative Medicine. 2006;3:201-207. 